\title{
A Study on Chronic Suppurative Otitis Media in a Tribal Area Medical College
}

\author{
Satyajit Mishra* \\ Department of E.N.T. \& Head and Neck Surgery, Bhima Bhoi Medical College, \\ Bolangir, Odisha, India \\ *Corresponding author
}

\section{Keywords}

Suppurative, Otitis media, Chronic,

Otorrhoea

Article Info

Accepted:

14 November 2020

Available Online:

10 December 2020

\section{A B S T R A C T}

Chronic suppurative otitis media (CSOM) is quite a common disease in Odisha. Because of lack of awareness, low socio economy status and scarcity of trained health care professionals in tribal areas, such patients do not get a proper treatment in time. As many a times this disease runs an indolent course, the patients do not give due importance to their symptoms and treat the symptoms as only a nuisance leading to a false security. Selftreatment and inadequate and improper treatment by non- qualified persons leads to high bacterial resistance and hence non response to conventional antibiotics in the disease occurs. A study was conducted in Department of E.N.T. \& Head and neck Surgery- S.L.N. Medical College, Koraput, between November 2017 TO October 2019 to gain a knowledge base about different patterns of presentations of CSOM in tribal based area so that a proper scientific approach can be taken up for their proper management as well as a policy change can take place for a better outcome. The patients were given information about their disease as well as the undertaken study and written informed consent was obtained prior to the study. CSOM is found to be prevalent in the second to third decades of life in people belonging to lower socio- economic status, mostly in male presenting with complaints of discharge from ear and reduced hearing along with this very few presented with features of complications like pain in ear and other neurological signs. CSOM being a very common disease in all age group in this area of Orissa that leads to much morbidity in poor patients. This study will guide health care professionals and policy makers to formulate a sound policy to alleviate this common and at times preventable disease.

\section{Introduction}

Chronic suppurative otitis media is a very common disease. It presents with persistent or recurrent ear discharge, progressive hearing loss and in complicated case otalgia, vertigo, headache, vomiting and altered sensorium. If untreated it presents with various complications which may be intra cranial and extra cranial. Although chronic suppurative otitis media has been a very common disease in all age group and both sexes, many a people neglect early symptoms leading to a chronicity of the disease. In developed countries, it is the most common indication for prescribing antibiotics ${ }^{1}$. It is the second 
most common disease of childhood after upper respiratory tract infection. As Koraput where this study was undertaken caters to tribal population, lots of cases of suppurative otitis media present to the hospital with varied presentation. As this is a nascent college, a study was undertaken to keep database about different aspects of this common disease for formulating a favorable protocol for the tribal people.

Chronic suppurative otitis media (CSOM) is an important middle ear disease since time immemorial $^{2}$.

Csom is defined as a chronic and persistent inflammation of mucoperiosteal lining of middle ear cleft. Middle ear cleft includes middle ear, mastoid air cell system and eustachean tube. As this space is anatomically a continuation of upper respiratory tract, any inflammation of the later will affect adversely the middle ear cleft. Upper respiratory tract infection is quite common in the tribal of this area, because of cold climate, hilly terrain, low socio economic status leading to poor body immunity and lack of proper health care facility. So, the incidence of chronic suppurative otitis media is also quite prevalent in this area.

CSOM is pathologically divide into two categories depending upon the site of location of the pathology: Tub tympanic and Attico antral. In the former category, the pathology is limited to eustachean tube and middle ear, while in the later group along with middle ear, mastoid air cell system is affected. In the tubo tympanic group as two way drainage path in the form of eustachean tube and perforated tympanic membrane is present, chances of complication is negligible. In attico antral group, mastoid process being a blind reservoir with aditus being the only communicating channel, there is stagnation of discharge leading to rapid multiplication of offending organisms leading to increased virulency of the later and complications. The aditus also gets blocked by inflammatory edema of middle ear mucosa leading to further narrowing the path of egress for the pus. Moreover in the attico antral group, choleateatoma and granulation tissue are the finding. Cholesteatoma because of its bone eroding property and granulation tissue because of its hyperemic osteoporotic activity leads to spread of disease outside temporal bone causing different intra cranial and extra cranial complications. Some of these complications are fatal. Different chemical mediators released by cholesteatoma may be offending too.

As the poor and ignorant patients are irregular in their treatment, habituated to pond bath and neglect symptoms chronicity develops. Inadequate treatment leads to antibiotic resistance, hearing loss and much morbidity. Because of the indolent symptoms in many cases, the patients do not attach much importance to the symptoms and neglect their health. As surgical treatment facility is not widely available, proper and permanent cure is also difficult to achieve.

The patients taken for this study were those attending department of E.N.T. \& head and neck Surgery- S.L.N. Medical College, Koraput between November 2017 TO October 2019. The present study took 920 no. of such cases. Data of the cases were included in the study after obtaining informed written consent.

The patients were thoroughly clinically examined as regard their symptoms in the following phases:

A thorough otolaryngological clinical examination and general examination

Hearing assessment 
Intraoperative middle ear and mastoid status (in operated case)

Pure tone audiometry was done in every case. X-ray of skull (lateral view) and PNS, CT scan temporal bone, routine haematological investigations and examination under microscope were done.

\section{Observation}

Table.1 Incidence of CSOM

\begin{tabular}{|l|c|c|c|}
\hline $\begin{array}{l}\text { Total } \\
\text { Patients in } \\
\text { E.N.T. OPD }\end{array}$ & $\begin{array}{c}\text { Total } \\
\text { no. of } \\
\text { SOM } \\
\text { cases }\end{array}$ & $\begin{array}{c}\text { Total no. } \\
\text { of cases of } \\
\text { CSOM }\end{array}$ & $\begin{array}{c}\text { Percentage } \\
\text { of CSOM } \\
\text { cases }\end{array}$ \\
\hline 13800 & 4600 & 920 & $20 \%$ \\
\hline
\end{tabular}

\section{Results and Discussion}

Out of 13800 no. of patients coming to outpatient dept. Of S.L.N. Medical College, Koraput between November 2017 TO October 2019, 4600 were detected to have suppurative otitis media and 920 of them were chronic suppurative otitis media as shown in Table 1. The percentage of patients in relation to suppurative otitis media was $20 \%$. Rest of the cases comprises acute suppurative otitis media, secretory otitis media etc.

Maximum number of patients 60\% (552) belongs to $2^{\text {nd }}$ and $3^{\text {rd }}$ decade followed by 30 to 40 years of age $(17 \%)$. Male preponderance was also noted, usually at a ratio of 3:1 across all age groups (Table 2).

The patients were divided into various socio economic status based on modified Kuppuswamy and U. Pareekh scale- 2019 (Rabbanie tariq wani, Journal of family medicine \& primary care-Wolter kluwer: socioeconomic status scale- modified Kuppuswamy \& U. Preekh 's scale updated for 2019-Aug 2020) and majority belongs to low socio-economic status (58\%). The combined factor of poverty and adverse financial condition delays their coming to hospital for health care. Moreover, in assessable terrain in tribal areas as well as lack of education leads to unawareness of the potential complications of the disease as well as curability of the disease. About $90 \%$ of the patients in this study reside in rural area and that may be reason for their delay in availing health care facility (Table 3 ).

As shown in the table above, $49 \%$ cases were agricultural workers followed by Industrial workers $(19.5 \%)$ and house wives. As this tribal area has got a rich population of agricultural workers, it is but natural that maximum no. of patients belongs to this category. Daily laborers also have a significant incidence of otitis media (Table 4).

$62 \%$ of the patients came with the finding of mucoid discharge and only $22 \%$ came with purulent discharge. The former group had duration of discharge for several months and the discharge used to be aggravated with episodes of upper airway infection. Only $12 \%$ had blood stained discharge. Dizziness was complained by $12(11 \%)$ patients. Central perforation in tympanic membrane was the commonest finding and it involved multiple quadrants. Attic retraction and posterior marginal perforation was the finding in $2 \%$ and $1 \%$ of cases respectively. As far as other signs are concerned, hearing loss was the commonest one in $89 \%$ cases, aural polyp and granulation in $1 \%$, mastoid tenderness in about $3 \%$ cases seen (Table 5 ).

As far as hearing is concerned, conductive hearing loss was found in $82 \%$ cases and mixed loss in $13 \%$ cases. Pure sensory neural loss was the finding in only $5 \%$ cases (Table $6)$.

More than $90 \%$ of the cases belong to safe variety and only $7 \%$ were of the unsafe kind (Table 7). 
Table.2 Age and sex incidence

\begin{tabular}{|c|c|c|c|c|}
\hline Age group in years & Male & Female & Total & Percentage \\
\hline $\mathbf{2 1 - 3 0}$ & 385 & 167 & 552 & $\mathbf{6 0}$ \\
\hline $\mathbf{3 1 - 4 0}$ & 89 & 67 & 156 & $\mathbf{1 7}$ \\
\hline $\mathbf{4 1 - 5 0}$ & 82 & 19 & 101 & $\mathbf{1 1}$ \\
\hline $\mathbf{5 1 - 6 0}$ & 42 & 22 & 64 & $\mathbf{7}$ \\
\hline $\mathbf{6 1 - 7 0}$ & $\mathbf{3 5}$ & $\mathbf{1 2}$ & $\mathbf{4 7}$ & $\mathbf{5}$ \\
\hline
\end{tabular}

Table.3 Socio- economic status

\begin{tabular}{|l|l|l|}
\hline Socioeconomic Status & No. of cases & Percentage \\
\hline Upper Class & 92 & $\mathbf{1 0 \%}$ \\
\hline Middle Class & 294 & $\mathbf{3 2 \%}$ \\
\hline Lower Class & $\mathbf{5 3 4}$ & $\mathbf{5 8 \%}$ \\
\hline
\end{tabular}

Table.4 Occupation

\begin{tabular}{|l|l|l|}
\hline Occupation & No. of Cases & Percentage \\
\hline Agricultural Worker & 459 & $\mathbf{4 9 \%}$ \\
\hline Laborer & 166 & $\mathbf{1 8 \%}$ \\
\hline Office Worker & 184 & $\mathbf{1 9 . 5 \%}$ \\
\hline House Wives & 111 & $\mathbf{1 3 . 5 \%}$ \\
\hline Total Cases & $\mathbf{9 2 0}$ & $\mathbf{1 0 0 . 0}$ \\
\hline
\end{tabular}

Table.5 Symptoms and signs

\begin{tabular}{|c|c|}
\hline SYMPTOMS \% SIGNS & NO. OF CASES \\
\hline Mucoid discharge & $570(62 \%)$ \\
\hline Purulent discharge & $203(22 \%)$ \\
\hline Mucopurulent discharge & $147(16 \%$ \\
\hline Dizziness & $12(13 \%)$ \\
\hline Blood stained discharge & $11(12 \%)$ \\
\hline Central Perforation & $856(93 \%)$ \\
\hline Single quadrant & $206(24 \%)$ \\
\hline Multiple quadrant & $479(56 \%)$ \\
\hline Subtotal & $171(20 \%)$ \\
\hline Attic Retraction & $22(2.39 \%)$ \\
\hline $\begin{array}{l}\text { Posterior marginal } \\
\text { perforation }\end{array}$ & $16(1.7 \%)$ \\
\hline Hearing loss & $819(89 \%)$ \\
\hline Mastoid tenderness & $27(2.98 \%)$ \\
\hline Post aural swelling & $9(1 \%)$ \\
\hline Granulation tissue & $16(1.7 \%)$ \\
\hline Polyp & $10(1.08 \%)$ \\
\hline Facial nerve paralysis & $02(0.2 \%)$ \\
\hline
\end{tabular}


Table.6 Types of hearing loss

\begin{tabular}{|l|l|}
\hline TYPE & $\begin{array}{l}\text { NO. OF } \\
\text { CASES }\end{array}$ \\
\hline Conductive & $\mathbf{7 5 4}(\mathbf{8 2} \%)$ \\
\hline Sensorineural & $\mathbf{4 6}(\mathbf{5 \%})$ \\
\hline Mixed & $\mathbf{1 2 0}(\mathbf{1 3 \%})$ \\
\hline Total & $\mathbf{9 2 0}$ \\
\hline
\end{tabular}

Table.7 Type of CSOM

\begin{tabular}{|l|l|}
\hline TYPE OF & NO. OF \\
CSOM & CASES \\
\hline Safe & $856(93 \%)$ \\
\hline Unsafe & $64(7 \%)$ \\
\hline Total & 920 \\
\hline
\end{tabular}

Out of 13800 no. of total patients attending OPD, 4600 were detected to have suppurative otitis media and 920 of them were chronic suppurative otitis media as shown in Table 1. The percentage of patients in relation to suppurative otitis media was $20 \%$. Sitashree et al., ${ }^{3}$ observed an incidence of $23.96 \%$ of their total OPD attendance suffering from suppurative otitismedia and $19.11 \%$ were having CSOM. This can be compared with that of Amit K. Verma et al., ${ }^{4}$ who in their study noted the incidence of CSOM to be $15.3 \%$ in a pediatric population. Browing GG et al., ${ }^{5}$ found the total prevalence of chronic otitis media to be $16 \%$.

Commonest age group to be affected is $2^{\text {nd }}$ and $3^{\text {rd }}$ decade followed by $3^{\text {rd }}$ and $4^{\text {th }}$ decade. Narve et al., ${ }^{6}$ had similar finding. Male preponderance was also noted, at a ratio of 3:1 across all age groups. Ahmed $\mathrm{M}$ Alabbais $^{7}$ in his study found male preponderance of CSOM cases i.e.54.16\%. Sitashree et al., had also male predominance finding. More no of suppurative otitis media cases in male population may be due to increased number of their attendance in hospital and participation in activities that predisposes them to upper air way infections like pond bathing and outdoor cold environment exposure. Majority belongs to low socio-economic status (58\%) as per modified Kuppuswamy and Pareekh scale2019. Narve et al., ${ }^{6}$ found $67 \%$ of their patients belonging to the lower socioeconomic group. Wakode et al., ${ }^{13}$ and Kamal et al., ${ }^{14}$ had also similar finding. This is comparable to that of Browning GG et al., ${ }^{5}$.They found higher prevalence of CSOM in lower socio economic groups with manual workers. Primary Health care is not a priority in people with a background of low socioeconomic status and they neglect common ailments like upper respiratory tract infections leading to multiple episodes of this infection in them, which in turn affects ear infection. Moreover, living in overcrowded space leads to cross infection. Another factor may be their low body immunity.

As shown in the table four above, $49 \%$ cases were agricultural workers followed by Industrial workers $(19.5 \%)$ and housewives. Browning et al., ${ }^{5}$ found higher prevalence of CSOM in manual workers.

Otorrohea which is either mucoid (62\%) or purulent (22\%) and in only a few cases blood stained $(12 \%)$ were commonest presenting features. Dizziness was complained by 12 
$(11 \%)$ patients. Central perforation in tympanic membrane involving multiple quadrants. Attic retraction and posterior marginal perforation were the findings. As far as other signs are concerned, hearing loss (89\%), aural polyp and granulation, mastoid tenderness were also noted. Similar findings were noted by V P Narveet 6 , Olatoke $\mathrm{F}^{8}$ and Altuntas A et al., ${ }^{9}$ in their series. Narve et al., .${ }^{6}$ found $(77 \%)$ of their cases had safe CSOM with central perforation while only 23 cases had attic perforation and granulation tissue or polypoidal tissue. Bhusal et al., ${ }^{12}$ had identical findings.

As far as hearing is concerned, conductive hearing loss was found in $82 \%$ cases and mixed loss in $13 \%$ cases. Pure sensory neural loss was the finding in only $5 \%$ cases. Seetashri $\mathrm{et}^{3}$ al found the incidence of conductive and mixed hearing loss in in their series in $60.35 \%, 39.65 \%$ of cases respectively. This too is comparable to finding of Ahmed M. Alabbasi ${ }^{7}$ et al., as their study found conductive hearing loss in $55.5 \%$ cases, mixed hearing loss in $44.3 \%$ cases and sensory neural loss in $16.6 \%$ cases. Ramanuj Bansal $^{11}$ in a study of 758 cases, found conductive hearing loss in $86.17 \%$ of cases. Minja $^{12}$ in a study of 189 CSOM cases noted conductive hearing loss in $73(82 \%)$ and sensorineural (SNHL) in $16(18 \%)$ cases. These findings are comparable to our study.

Chronic suppurative otitis media is a common disease in the tribal population and male in the second and third decade are predominant suffers. Maximum number of such patients belong to low socio economic status. Persistent or recurrent discharge from ear, decreased hearing, dizziness, otalgia, swelling in the post aural area with tenderness over the area are the common symptoms. Central perforation involving multiple quadrant of tympanic membrane, conductive hearing loss are usual findings on examination.
A proper history taking including social status and cultural background and thorough clinical evaluation leads to exact diagnosis of this common condition. As the poor patients from a tribal belt suffer a lot due to this disease as they are ignorant about the potential complications as well as preventive measures, loss of precious manpower is always a probability. Therefore, a shift on public policy to impart holistic care to the unfortunate people of this tribal area will go a long way in alleviating their suffering. Hopefully, the data gathered through this study will propel us in a right direction to achieve this.

\section{References}

1. Peter S. Morris (Upper respiratory tract infections including otitis media); Pediatric clinic of North America 56(2009); page. 101-117.

2. McKenezie, W. and Brothwell, D disease of the ear. In: Diseases of antiquity, edited by D. Brothwell and T. Standison, Springfield. Charles C. Thomas. 1967, PP.464-73.

3. Sitashree Sethy, Krishna Chandra Mallik. "Clinico-Pathological Study of Extra cranial Complications of Middle Ear Infections". Journal of Evolution of Medical and Dental Sciences 2014; Vol. 3, Issue 13, March31; Page: 3460-3467

4. Amit K. Verma et al., Epidemiology of chronic suppurative otitis media and deafness in a rural area and developing an intervention strategy. Indian $\mathbf{J}$ Pediatr. 1995 Nov-Dec; 62(6):725-9.

5. Browning GG, Gatehouse S. The prevalence of middle ear disease in the adult British population. Clin Otolaryngol Allied Sci. 1992 Aug; 17(4): 317-21.

6. V.P. Narve, Pallavi Gupta, Rajveer Basu, Manish Sachan, Kavish Jhawar, Freni J.K, Mohit Punjabi. "Clinicopathological study of 100 cases of chronic suppurative otitis media in tertiary health care 
centre". Journal of Evolution of Medical and Dental Sciences 2013; Vol2, Issue 33, August 19; Page: 6169-6175.

7. Ahmed M. Alabbasi, Ihsan E. Alsaimary, Jassim M Najim. Prevalence and patterns of chronic suppurative otitis media and hearing impairment in Basrah city. Journal of Medicine and Medical sciences 2010; 1(4): 129-133.

8. Olatoke F, Ologe FE, Nwawolo CC, Saka MJ. The prevalence of hearing loss among school children with chronic suppurative otitis media in Nigeria, and its effect on academic performance. Ear Nose Throat J. 2008 Dec, 87(12): E19.

9. Altuntas A, Asian A, Eren N, Unal A, Nalca Y, Susceptibility of microorganisms isolated from chronic suppurative otitis media to ciprofloxacin, Eur Arch Otorhinolaryngol (1996) 253:364-366

10. Bhusal CL, Guragain RP, Shrivastava RP. Size of tympanic membrane perforation and hearing loss. JNMA J
Nepal Med Assoc. 2006; 45(161): 16772.

11. Ramanuj Bansal and Anoop Raj. Hearing loss in rural population: The etiology. Indian J Otolaryngol Head Neck Surg. 1998 April; 50(2): 147-155.

12. Minja BM, Machemba A. Prevalence of otitis media, hearing impairment and cerumen impaction among school children in rural and urban Dares Salam, TanZania. Int J Pediatr Otorhinolaryngol 1996;37:29-34

13. RT. Wakode, S.V. Joshi, S.H. Gawarle, Chronic suppurative otitis media in school going children, Indian Journal of Otolaryngology and Head and Neck, Surgery, 2006, 58(2), 152- 155.

14. Kamal N, Joarder Ah, Chowdhury AA, Khan AW. Prevalence of chronic suppurative otitis media among the children living in two selected slums of Dhaka City. Bangladesh Med Res Counc Bull 2004, 30(3): 95-104.

\section{How to cite this article:}

Satyajit Mishra. 2020. A Study on Chronic Suppurative Otitis Media in a Tribal Area Medical College. Int.J.Curr.Microbiol.App.Sci. 9(12): 1851-1857.

doi: https://doi.org/10.20546/ijcmas.2020.912.220 